\title{
The Cranes of Last Mountain Lake
}

by Stuart Keith, American Museum of Natural History, New York

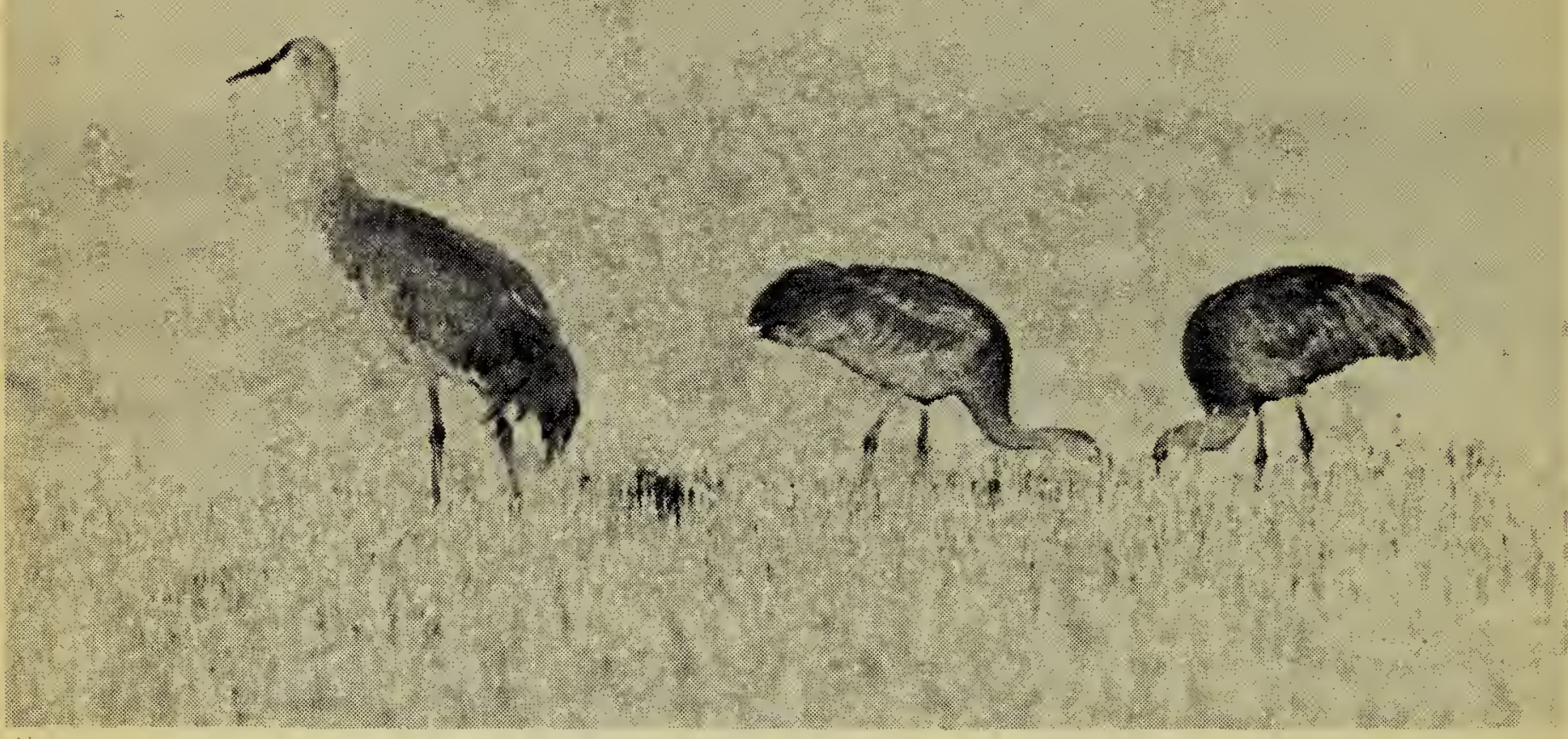

Photo by F. W. Lahrman

As the sun set over the prairies, a great silence seemed to descend. The stillness was broken only by the dry calls of the Savannah Sparrows which scuttled in and out of the bushes at the edge of the field. From the low rise on which we were standing the broad sweep of the prairies stretched out in every direction. Behind us were the shallow, marshy waters of the northern end of Last Mountain Lake. In front of us the sun was setting in a blaze of red and purple.

A whistlie of wings cut through the quiet air. A late party of ducks hard left the lake and was helading for the stubbles. They went over, and the stillness returned. Even the sparrows now were quiet. We waited tensely.

Gradually we became aware of a low murmur which seemed to come from the fields some distance in front of us. The murmur grew louder, and soon it became a wild clamor as thousands of excited voices joined in the chorus. Sitill we waited.

"Here they come," said my wife excitedly. Outlined against the pink sky, a dark line of birds was flapping towards us. The line was followed by another and another, until the whole sky was full of them, and the air was filled with their cries. This was what we had come across half a continent to see. Fifteen thousand Sandhill Cranes were coming to roost.

"Lucky people who live in Saskatchewan, to have all this on their doorstep," I thought.

Saskatchewan is, indeed, a magic word to anyone interested in cranes, a sort of never-never land where one can see ten times as many cranes in one minute as one has ever seen before in one's life. It is also famous as one of the two stopover places for the very rare Whooping Crane on its long flight from Wood Buffalo Park, Alberta, to the coast of Texas. We looked eagerly among the thousands of Sandhills, hoping to see one of the great white birds. But we saw none.

It is not only crane specialists who know about the cranes of Saskatchewan. They are fast becoming known among the ornithologists and conservationists of the whole continent, especially since the members of the American Ornithologists'. Union went on a special field trip to see them after their conference at Regina in 1959. When I was leaving New York on my way to Saskatchewan, several people asked me if I 
didn't need someone to go along and carry my camera!

The cranes were coming over now in ever greater numbers, line after line, group after group, calling as they came. The call of the cranes is one of the wildest and most evocative sounds in nature, as beautiful to my ears as the lonely wail of a loon at dusk. It ranges from the loud clarion-like call of excitement as the birds leave the roost at dawn to the low guttural notes of family conversation. Like the yelp of the coyote, it is one of the loveliest and most characteristic sounds of the prairies.

At the Aransas Refuge in Texas, where the last remaining Whooping Cranes come to spend the winter, thousands of visitors come every year to see the birds. The Whooping Crane is probably the most famous bird in North America. The birds are closely guarded, and no one, birdwatchers included, is allowed to disturb them. A special observation tower, equipped with high-powered telescope, has been built so that visitors can wlatch the birds from a distance without disturbing them.

As the Sandhill Cranes came in to Last Mountain Lake, I thought how wonderful it would be if people from all over the country could come and see them just as I was seeing them. It is truly one of the great natural phenomena of the continent. Not only bird-watchers but everyone interested in the outdoors should have a chance to see them. Millions and millions of people visit the National Parks every year-why nat Last Mountain Lake too? To begin with, it has the distinction of being the oldest bird sanctuary on the whole continent. Besides the cranes, there are pelicans, geese, ducks, and a host of other birds. With proper care of the sanctuary and good advertising, it could rank as one of Saskatchewan's top attractions for tourists.

The sun had dipped below the western horizon now, and the orange clouds were turning to pale pink and then gray. Still the cranes were flying in, but in smaller numbers. Most of them were already crowded along the shores of the lake, talking excitedly but in ever-decreasing tones. Soon the last few stragglers arrived. The talking had subsided into a murmur, and gradually it died away altogether. The great evening flight of the cranes had ended, and the birds were going to sleep. It had been one of the greatest experiences I had ever had with birds.

Reluctantly, we turned to go.
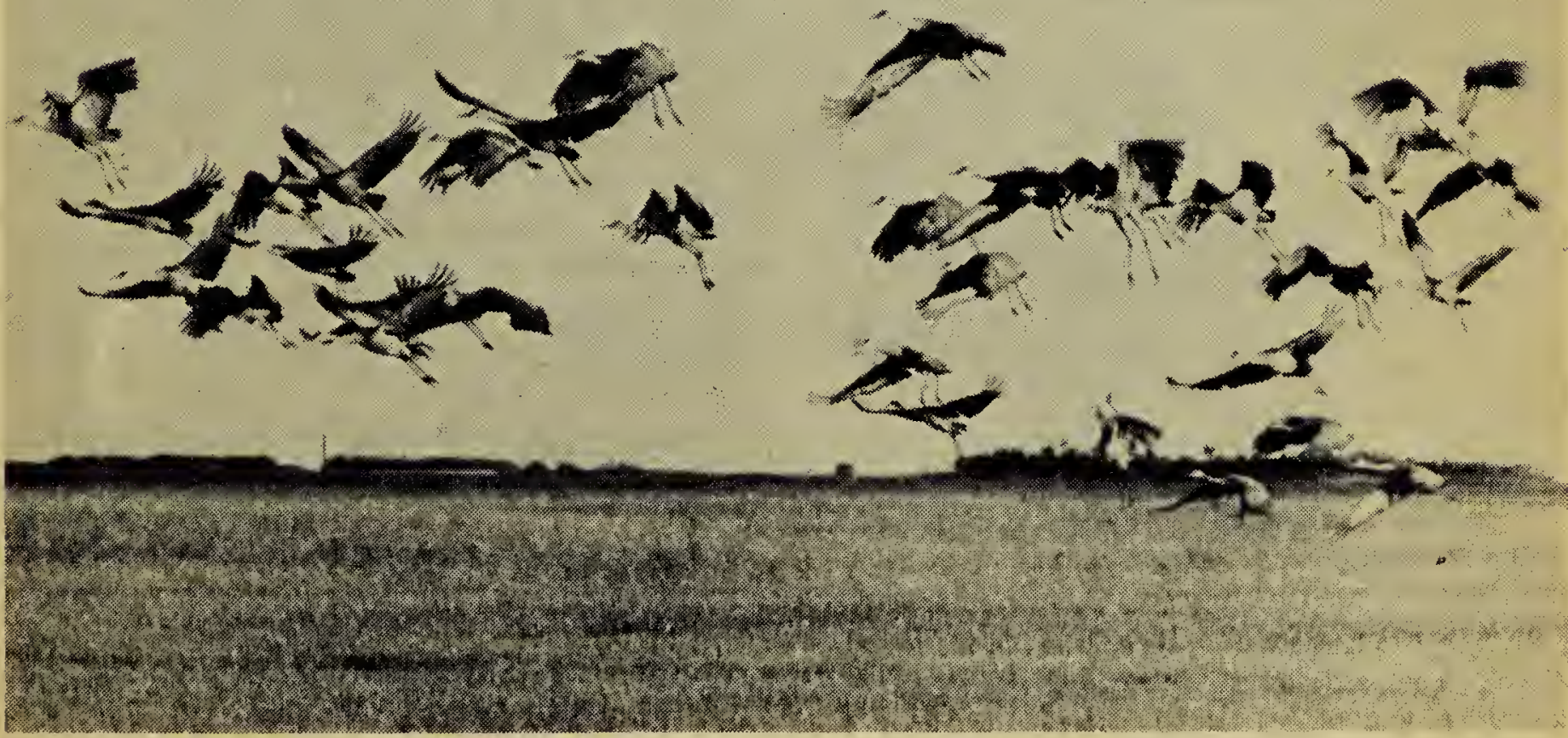

Photo by F. W. Lahrman 